Blomberg, E., S. B. Davis, J. Mangelinckx, and K. Sullivan. 2018. Detecting capture-related mortality in radio-marked birds following release. Avian Conservation and Ecology 13(1):5. https://doi.org/10.5751/ACE-01147-130105

Copyright (C) 2018 by the author(s). Published here under license by the Resilience Alliance.

Methodology

\title{
Detecting capture-related mortality in radio-marked birds following release
}

\author{
Erik J. Blomberg ${ }^{1}$, Samantha B. Davis ${ }^{1}$, Joelle Mangelinckx ${ }^{1}$ and Kelsey Sullivan ${ }^{2}$ \\ ${ }^{1}$ University of Maine, ${ }^{2}$ Maine Department of Inland Fisheries and Wildlife
}

\begin{abstract}
A fundamental assumption of avian survival analysis is that the act of capture, handling, and marking birds does not affect subsequent survival. This assumption is violated when animals experience injury, physiological stress, or disorientation during capture and handling that increases their mortality risk following release. Such capture-related effects must be accounted for during analysis, typically by censoring individuals from the survival history, to avoid biasing the resulting survival estimates. We reviewed studies of radio-marked upland game birds to characterize researcher approaches for addressing short-term effects of capture on survival, and used data from a study of Ruffed Grouse (Bonasa umbellus) to illustrate an empirical approach for evaluating such effects and identifying time thresholds to censor individuals that die shortly following release. A majority of studies (65\%) reported using some form of censoring for mortality that occurred within one to three weeks after release, although only $8 \%$ of studies reported an empirical approach to identify a threshold for censorship. We found that Ruffed Grouse mortality was greater from one to six days following release when compared with 7 to 30 days. This threshold, and the proportion of birds censored as a result of it, is consistent with a number of previous studies of radio-marked Ruffed Grouse. We also found that short-term mortality of Ruffed Grouse following release was reduced by checking traps twice each day and by adequately concealing traps. We recommend that future studies of radio-marked birds employ empirical methods for detecting postrelease mortality thresholds, which will allow for reduced bias while minimizing unnecessary censorship of birds that die for reasons unrelated to capture.
\end{abstract}

\section{Détection de la mortalité attribuable à la capture chez des oiseaux marqués par radiotélémétrie}

RÉSUMÉ. L'analyse de la survie des oiseaux repose sur l'hypothèse de base voulant que l'acte de capturer, manipuler et marquer des oiseaux n'affecte pas leur survie subséquente. Cette hypothèse est violée lorsque les animaux subissent des blessures, un stress physiologique ou une désorientation pendant la capture et la manipulation, puisque leur risque de mortalité une fois relâchés augmente du coup. Ces effets imputables à la capture doivent être considérés au moment des analyses, en suivant habituellement l'histoire de survie des individus, afin que les estimations de la survie ne soient pas biaisées. Nous avons passé en revue des études réalisées sur des oiseaux terrestres considérés comme gibier afin de caractériser les approches utilisées par les chercheurs pour tenir compte des effets à court terme de la capture sur la survie. Nous avons également utilisé les données d'une étude sur la Gélinotte huppé (Bonasa umbellus) afin de présenter une approche empirique destinée à évaluer ces effets et à déterminer les seuils temporels où on devrait interrompre le suivi des individus qui meurent rapidement une fois relâchés. La majorité des études (65\%) rapportaient avoir interrompu de diverses façons le suivi d'individus dont la mortalité était survenue à l'intérieur d'une à trois semaines après la remise en liberté, mais on rapportait avoir utilisé une méthode empirique pour déterminer un seuil pour cette interruption de suivi dans seulement $8 \%$ des cas. Nous avons constaté que la mortalité des gélinottes était plus élevée dans la période allant du 1er au 6e jour suivant leur remise en liberté, que dans la période allant du 7e au 30e jour. Ce seuil, et la proportion d'oiseaux dont le suivi a été interrompu en fonction de celui-ci, concordait avec bon nombre d'études antérieures dans lesquelles des gélinottes étaient marquées par radiotélémétrie. Nous avons aussi trouvé que la mortalité survenant à court terme une fois les gélinottes relâchées était réduite si l'on vérifiait les trappes deux fois par jour et si l'on camouflait celles-ci adéquatement. Nous recommandons que les études futures sur des oiseaux marqués par radiotélémétrie utilisent des méthodes empiriques pour déterminer les seuils de mortalité après remise en liberté, ce qui permettra de réduire les biais tout en minimisant les interruptions non nécessaires dans le suivi des oiseaux qui meurent pour des raisons non liées à la capture.

Key Words: capture effects; galliform; game birds; mortality; radio-telemetry; Ruffed Grouse; survival

\section{INTRODUCTION}

Many aspects of avian biology, such as breeding behavior and habitat use, influence mortality risk and thus affect population dynamics. These processes are illuminated through survival analysis (Murray 2006, Murray and Patterson 2006, Sandercock
2006), which seeks to both quantify rates of period-specific survival and to evaluate sources of variation in mortality risk among individuals. Most survival studies involve physical capture, handling, and marking of birds, with some notable exceptions, e.g., genetic mark-recapture. All such studies 
implicitly assume that mortality risk to marked individuals is representative of the population as a whole (Pollock and Raveling 1982, Esler et al. 2000, Murray 2006). This assumption may be violated if the act of capturing, handling, and/or marking a bird increases its mortality risk following release, in which case estimates of survival are biased low. Evaluating this potential bias, and if necessary accounting for it, are therefore important components of avian survival research.

Numerous studies have addressed potential effects of capture and marking on individual species (e.g., Esler et al. 2000, Dugger et al. 2006, Hagen et al. 2006, Holt et al. 2009, Gibson et al. 2013), and a number of synthesis reviews have been published for both birds (e.g., Calvo and Furness 1992, Barron et al. 2010) and animals in general (e.g., Murray and Fuller 2000). Deleterious effects of capture and marking can be separated into two discrete categories: effects that are short term and acute, and effects that are long term and chronic (Holt et al. 2009). Long-term effects are normally associated with reductions in annual survival or behavior attributed to carrying the mark itself. For example, if the attachment of a radio-collar impacts behavior, thus altering potential breeding success (e.g., Gibson et al. 2013, Fremgen et al. 2017). Evaluating long-term effects normally requires an experimental design using multiple marking techniques (e.g., radio-marked vs. banded-only; Barron et al. 2010). Short-term effects, in contrast, may result from a variety of factors associated with capture, handling, and/or marking. Following release, a bird may succumb to injuries (either observed or latent) that were incurred during capture (Grisham et al. 2015), may die as a result physiological complications due to capture and handling, i.e., capture myopathy (Arnemo et al. 2006), or may die via indirect causes, such as predation, that occur because the bird is disoriented after release or is acclimating to presence of the mark. Hereafter we will use the term capture effects to refer to this suite of potential short-term impacts associated with capture, handling, marking, and release.

Understanding capture effects can be challenging for studies informed solely by live observations, e.g., live recapture or band reading (Sandercock 2006), where mortality itself is rarely observed. Radio-telemetry studies differ in that both live and dead status are used to inform survival estimates (Murray 2006), thus offering an ability to evaluate timing of death relative to release and infer whether death may have been related to capture. This in turn presents a series of decision points to researchers, where they must choose whether or not to remove individuals that die shortly after release from the survival history, i.e., left-censoring, and if so, what amount of time must pass before mortality is presumably not associated with capture. The approaches used are variable among researchers, and are often determined subjectively, despite that empirical evidence from data can be used to inform the decision process (Holt et al. 2009). If capture effects exist, survival probabilities should be lower immediately following release but increase predictably through time, and these temporal patterns should be detectable using standard approaches to survival analysis and appropriate time scales.

Our objective for this research was to summarize the range of approaches used by researchers when addressing capture effects on survival during radio-telemetry studies, and to present a systematic method for detecting thresholds of postrelease mortality to better-inform future work. We reviewed recent (2006-2017) literature from studies of upland game birds to characterize contemporary approaches to this issue, and we expected that the majority of researchers would use arbitrary time thresholds for left-censoring birds, or would not censor birds at all. We chose to focus our review on game birds because they are often studied using radio telemetry, and tend to share a similar suite of methods for capture and marking across species. We then used data from a three-year study of radio-marked Ruffed Grouse (Bonasa umbellus), a widely distributed gamebird in North America that has been the focus of numerous telemetry studies (Small et al. 1991, Gutierrez et al. 2003, Yoder et al. 2004, Devers et al. 2007, Skrip et al. 2011), to illustrate a data-driven approach to evaluate capture effects and thresholds of postrelease mortality. Here, we approached the analysis with an a priori hypothesis that realized thresholds in postrelease mortality would match those commonly cited in Ruffed Grouse research. Our work compliments and expands on prior similar assessments (e.g., Holt et al. 2009) by incorporating more recent literature and a broader suite of species, as well as by using an expanded suite of analytical tools for detecting threshold effects from radio-telemetry data.

\section{METHODS}

\section{Literature review}

We conducted a review of upland game bird survival studies to quantify the frequency at which researchers used differing methods for addressing capture effects on survival. We focused our review on publications that used radio-telemetry to detect mortality and estimate survival. Although this constraint excluded studies that used other methods to estimate survival, e.g., banding and capture-mark-recapture, we presumed that detection of immediate postrelease mortality was unlikely in most such studies because they rely on live detections, or are based on hunter recoveries, of marked birds. We conducted our search with Google Scholar (https://scholar.google.com/), using combinations of the following key words: radio telemetry; survival; grouse; prairie chicken; quail; bobwhite; wild turkey. We restricted our review to peer-reviewed articles published in journals or as symposia proceedings from the period 2006 to 2017. We did not consider earlier works in part to narrow our search window, which made the review more practical while still generating a substantive sample of published work. More importantly, our use of this date range ensured a review of contemporary studies that best reflected current practices, both field and analytical. See Holt et al. (2009) for a similar review and evaluation of earlier works specifically related to Northern Bobwhite (Colinus virginianus). Our intent for this exercise was not to produce an exhaustive review of the literature on this subject, but rather to generate a sample of studies that was sufficiently large to be representative of the approaches used by game bird researchers.

For each paper, we recorded the study species and classified the approach to postrelease censorship into one of four categories: (1) investigators did not censor any mortalities, (2) censored based on field evidence that suggested cause of death was related 
to capture, (3) censored based on an a priori time threshold, or (4) censored after using a post hoc assessment of the appropriate time threshold. If a paper did not explicitly report any approach to censoring, we assumed that category 1 (did not censor) was the approach used. For category 3 (a priori threshold) we further distinguished among studies that censored all individuals prior to the threshold date, i.e., delayed entrance into the survival history, and studies that only censored individuals that did not survive the censor period. The distinction between these two approaches is that surviving birds contributed data to survival estimates during the censor period in the latter approach, but not the former. We recorded the threshold length in days for each study, and also recorded the proportion of captured birds that were censored from the analysis when the information provided in the paper allowed for it. In all cases we focus exclusively on censoring of bird deaths that occurred shortly ( $<30$ days) following release that were potentially associated with capture. Many studies describe truncation of survival histories, i.e., rightcensoring (Murray 2006) because of other factors such as transmitter failure or emigration from the study area, and those approaches were not the purpose of our review. Moreover we did not consider handicaps associated with long-term effects of radiomarking in this study, which have been reviewed elsewhere (Barron et al. 2010).

\section{Example application}

\section{Field methods}

We captured Ruffed Grouse in two study areas in central Maine, USA, during 2014-2016. Our capture season consisted primarily of the months of August and September, although we trapped a few birds during October, April, and May. We used modified lilypad traps following Gullion (1965) that were similar in design to those used in most other recent Ruffed Grouse research (Devers et al. 2007, Skrip et al. 2011). Traps normally consisted of two round trap bodies constructed of welded wire and covered with a piece of mesh fabric, which were connected by an approximately $20 \mathrm{~m}$ long wire drift fence that lead into one-way wire funnels. We checked traps once each day immediately before sunset during 2014, and in 2015 and 2016 we increased our trap check frequency to two times each day, with the additional check occurring during midmorning, approximately four hours after sunrise. Evening checks were intended to prevent birds from remaining in traps overnight, and late morning traps were intended to reduce the length of time birds spent in traps if they were captured early in the day. All traps were concealed by piling natural debris, e.g., branches and leaf litter, on top of the trap, and in 2015 and 2016 we increased the level of concealment by piling substantially more materials on and around the sides of the trap body. Both of these modifications were designed to reduce the risk of self-inflicted injury to captured birds; more frequent trap checks reduced the amount of time a bird spent in the trap body following capture, and increased concealment was intended to improve the birds' sense of security while in the trap. We determined age of each captured bird as hatch-year $(<1$ year of age) or after-hatch-year ( $>1$ year of age) and sex based on feather characteristics (Davis 1969). All birds were fitted with an aluminum leg band and a 12g-radio transmitter with a necklace-style attachment, which featured a mortality sensor that increased the radio signal pulse rate when the collar remained motionless for $>8$ hours, and we did not radio-mark individuals weighing $\leq 375 \mathrm{~g}$. All capture and handling of Ruffed Grouse was approved by the Institutional Animal Care and Use Committee at the University of Maine (IACUC Protocol A2014-03-06).

We monitored all radio-marked Ruffed Grouse using hand-held radio receivers every one to three days for the first 30 days following release, and recorded and investigated mortalities when they occurred to confirm the bird had died. We relied strictly on the radio signal for monitoring and did not flush or otherwise disturb birds after release, unless they were recaptured. Both the radio collar and leg band were printed with a toll-free phone number for hunters to report marked Ruffed Grouse to the University of Maine if they were harvested during the hunting season, which began 1 October during each study year. Some of our mortality data reflected harvest that occurred within 30 days of capture, and we did not distinguish between harvest and nonharvest mortality for the purpose of this study.

\section{Data analysis}

We analyzed daily survival probabilities of radio-marked Ruffed Grouse using nest survival models, implemented in Program MARK (White and Burnham 1999) via the R (R Core Team 2017) package RMark (Laake 2016). We distilled our monitoring data into individual survival histories for each radio-marked bird, where day 1 of the history reflected the day of capture, rather than the calendar date, i.e., all histories began on day 1 . Sometimes a Ruffed Grouse was captured $>1$ time within a single trapping season, in which case we right-censored the bird's original history on the day prior to its subsequent capture, and began a new history (as day 1) that reflected the time elapsed since the second capture. In cases where we lost radio contact with a bird, e.g., due to a radio malfunction, we right-censored that bird from the survival history following the last day we obtained a signal from it. All histories were truncated 30 days after capture, which we chose as an end point for this analysis because we were interested exclusively in short-term effects of capture; using a time period of greater duration could potentially confound results with other longer term temporal processes that were unrelated to capture, e.g., seasonal variability.

We approached our analysis in two phases. During the first phase, we tested for and identified potential sources of heterogeneity in survival that that were not explicitly tied to capture effects. These included year, bird age, bird sex, study area, and date of capture. We included the ordinal date of capture in the analysis to account for the possibility of seasonal changes in survival, given that our primary capture period spanned two calendar months. Year was potentially informative, with respect to capture effects, because of the changes we implemented in trapping protocols between our first and second/third study years. We constructed single term models based on each of these five variables, and compared them against each other and a null model (intercept only). In all analyses we made comparisons among models using AIC $_{\mathrm{c}}$ (Anderson and Burnham 2002), where we considered models to have similar support when they fell within 2.0 $\mathrm{AIC}_{\mathrm{c}}$ units of a contrasting model, e.g., the null model. We also examined confidence intervals around parameter coefficients, and gauged parameter support based on whether $95 \%$ confidence intervals overlapped 0.0 . 
In our second phase of analysis, we included all variables supported during phase 1 as a base model structure, and then considered time effects on postrelease survival that took one of three forms. First, we considered a model where we allowed full independence in survival probability among each of the 30 days postcapture. Although this model was highly parameterized and thus unlikely to be competitive based on $\mathrm{AIC}_{\mathrm{c}}$, it was nevertheless important because it allowed us to visualize the full range of variability in daily survival probabilities independent of any modeled constraints. Second, we fit three forms of models that were intended to reflect systematic temporal trends in daily survival postrelease; these models included both linear and quadratic trends on daily survival probability, as well as a model where we applied a natural log transformation to the numeric value of days postrelease. This later model form produced a nonlinear pattern that was similar to the quadratic model, but has the added benefit of not forcing nonlinear trends at both minimum and maximum values for the predictor variable, as can often happen with a quadratic effect. Collectively these models were designed to test for systematic increase in daily survival throughout the 30-day postrelease period, which would be indicative of a generally diminishing effect of capture and marking. Finally, we explored a series of models where we specified a threshold point in which the daily survival probability was allowed to vary before and after the threshold, but where within the respective time intervals on either side of the threshold survival was constant. These models allowed us to test for shifts in survival that were indicative of the most appropriate threshold date to use when censoring postrelease mortalities. We constructed one model for each potential threshold, beginning with day 2 and continuing through day 29. Although this approach results in a relatively large number of models, it also selects a threshold in postrelease survival that is both explicit and empirically defined. In contrast, for models that allow full independence in survival estimates, or that force constrained trends, thresholds must be interpreted qualitatively based on patterns in the resulting survival estimates.

For the second phase of analysis we made two assessments of model selection results, one in which we evaluated the whole suite of models to identify the best-supported temporal structure, and a second where we compared results among only the threshold models. We used criterion for model selection and variable importance as described above, and we also calculated $\mathrm{AIC}_{\mathrm{c}}$ model weights ( $w_{i}$; Anderson and Burnham 2002) from among only the subset of threshold models to aid in interpretation of threshold timing. We used both model deviance and $w_{i}$ to evaluate relative support among competing threshold value models; deviance was appropriate for model selection in this specific case because all threshold models shared a common number of parameters. Finally we computed an $R_{-}^{2}$ Dev statistic as

$$
R^{2} \text { Dev }=\frac{\text { Dev }_{\text {Null }}-\text { Dev }_{\text {covariate }}}{\text { Dev }_{\text {Null }}-\text { Dev }_{\text {Full }}}
$$

which yields an approximation of the proportional temporal variance that is explained by a time-structured covariate (Grosbois et al. 2008). In our case, the null model contained the base model structure with no within-year temporal variation. The full model allowed full daily variability in postrelease survival, and the covariate of interest was our best-supported threshold model.

\section{RESULTS}

\section{Literature review}

We reviewed 58 publications representing 12 species of upland birds (Table A1.1). Two of these publications contained two distinct analyses, and so our review consisted of 60 total survival analyses. Sixty-five percent of studies $(n=33)$ applied one of the three censoring criteria to birds that died postrelease, whereas $45 \%$ of studies $(n=27)$ did not report censoring postrelease mortalities. The most common approach to censoring involved use of an a priori censoring period, which was applied in $35 \%$ of studies $(n=23)$. Among studies using this approach, most removed birds from analysis that died prior to the postrelease date threshold $(\mathrm{n}=17)$, whereas in a smaller number of studies $(\mathrm{n}=$ 6) authors reported withholding all birds from survival histories until they passed the date threshold. Censoring that was based on field evidence $(n=5)$, and systematic approaches to detect postrelease survival thresholds $(n=5)$, each were represented by $8 \%$ of studies. The length of censoring periods among studies that incorporated them (either a priori or systematically derived) ranged from 1 to 21 days, with a mean of 9.1 days postrelease. Only 11 studies reported sufficient information to calculate the proportion of individuals that were censored because of postrelease mortality, and those values ranged from 0.015 to 0.160 , with a mean of 0.074 .

\section{Survival analysis}

We captured and radio-marked 294 individual Ruffed Grouse, and recorded 56 mortalities that occurred during the first 30 days after release. Our first stage of analysis identified study year and bird age as important predictors of postrelease survival, whereas date of capture, study area, and sex were not related to survival (Table 1). Survival was lowest following releases that occurred during the first year of our study, whereas survival was greater during the second ( $\beta=0.65 ; 95 \% \mathrm{CI}=0.03$ to 1.27 ) and third years $(\beta=0.84 ; 95 \% \mathrm{CI}=0.03$ to 1.66$)$. This resulted in an approximately 0.006 increase in the average daily survival probability during years 2 and 3 , compared to year 1 . The singleterm age model was within $2.0 \mathrm{AIC}_{\mathrm{c}}$ of the null model, and suggested that daily survival of hatch-year birds was reduced by approximately 0.003 compared to after-hatch-year birds. However, 95\% confidence intervals of the coefficient overlapped $0.0(\beta=-0.36 ; 95 \% \mathrm{CI}=-0.90$ to 0.17$)$ and so support for the age effect was not equivocal. We nevertheless elected to retain the age effect, along with the year effect, in the second stage of analysis, because independent analysis of our larger telemetry dataset for this system demonstrate clear differences in survival among age classes (Davis 2017).

In our second stage of analysis we found the greatest support for a survival threshold that occurred between six and seven days following release (Fig. 1). The second-most support was for a model that identified a threshold between days 10 and 11 , however this model was $2.53 \mathrm{AIC}_{\mathrm{c}}$ units from the day 6 threshold model, and thus was not competitive based on our criterion of $2.0 \mathrm{AIC}_{\mathrm{c}}$ (Table 1). The day 6 threshold model also had the lowest model 
Table 1. Model selection results for nest survival analyses that describe the daily survival probability of Ruffed Grouse (Bonasa umbellus) for the first 30 days following release and radiomarking. Models were implemented in Program MARK using the R package RMark (Laake 2016). Temporal models took one of three forms: a model allowing full daily variation, daily trend models (linear, quadratic, natural $\log$ ), and a series of models identifying discrete threshold points of postrelease mortality.

\begin{tabular}{|c|c|c|c|c|}
\hline$\overline{\text { Model }^{\dagger}}$ & $\mathrm{AIC}_{\mathrm{c}}$ & $\Delta \mathrm{AIC}_{\mathrm{c}}$ & $\mathrm{K}$ & Deviance \\
\hline Quadratic Trend + Base & 615.14 & 0.00 & 6 & 603.13 \\
\hline Linear Trend + Base & 615.92 & 0.78 & 5 & 605.91 \\
\hline LN(Day) + Base & 617.31 & 2.17 & 5 & 607.30 \\
\hline Day $6+$ Base & 619.50 & 4.35 & 5 & 609.49 \\
\hline Day $10+$ Base & 622.02 & 6.88 & 5 & 612.02 \\
\hline Day $9+$ Base & 622.48 & 7.34 & 5 & 612.48 \\
\hline Day $5+$ Base & 623.99 & 8.84 & 5 & 613.98 \\
\hline Day $7+$ Base & 624.80 & 9.65 & 5 & 614.79 \\
\hline Day $11+$ Base & 624.85 & 9.71 & 5 & 614.84 \\
\hline Day $8+$ Base & 625.78 & 10.64 & 5 & 615.77 \\
\hline Day $12+$ Base & 627.29 & 12.14 & 5 & 617.28 \\
\hline Day $13+$ Base & 629.37 & 14.23 & 5 & 619.37 \\
\hline Day $4+$ Base & 630.55 & 15.40 & 5 & 620.54 \\
\hline Day $14+$ Base & 631.15 & 16.01 & 5 & 621.15 \\
\hline Day $15+$ Base & 636.31 & 21.17 & 5 & 626.31 \\
\hline Day $3+$ Base & 638.64 & 23.49 & 5 & 628.63 \\
\hline Day $17+$ Base & 638.64 & 23.50 & 5 & 628.63 \\
\hline Day $16+$ Base & 641.01 & 25.86 & 5 & 631.00 \\
\hline Day $2+$ Base & 642.09 & 26.95 & 5 & 632.09 \\
\hline Day $18+$ Base & 643.01 & 27.87 & 5 & 633.00 \\
\hline Day $19+$ Base & 647.04 & 31.89 & 5 & 637.03 \\
\hline Day $1+$ Base & 649.76 & 34.62 & 5 & 639.75 \\
\hline Day (full) + Base & 649.94 & 34.80 & 32 & 585.67 \\
\hline Day $20+$ Base & 650.73 & 35.58 & 5 & 640.72 \\
\hline Day $21+$ Base & 651.33 & 36.19 & 5 & 641.32 \\
\hline Day $22+$ Base & 654.65 & 39.51 & 5 & 644.65 \\
\hline Day $25+$ Base & 655.04 & 39.89 & 5 & 645.03 \\
\hline Day $23+$ Base & 655.09 & 39.94 & 5 & 645.08 \\
\hline Day $24+$ Base & 655.28 & 40.14 & 5 & 645.28 \\
\hline Day $26+$ Base & 658.40 & 43.26 & 5 & 648.39 \\
\hline Day $27+$ Base & 661.39 & 46.25 & 5 & 651.38 \\
\hline Base & 662.08 & 46.94 & 4 & 654.08 \\
\hline Year & 662.80 & 47.66 & 3 & 656.79 \\
\hline Day $28+$ Base & 663.67 & 48.53 & 5 & 653.66 \\
\hline Null & 665.95 & 50.81 & 1 & 663.95 \\
\hline Age & 666.15 & 51.01 & 2 & 662.15 \\
\hline Date of Capture & 666.52 & 51.37 & 2 & 662.51 \\
\hline Sex & 667.49 & 52.35 & 2 & 663.49 \\
\hline Study Area & 667.88 & 52.73 & 2 & 663.87 \\
\hline
\end{tabular}

${ }^{\dagger}$ All time-structured models (full daily variation, day thresholds, trends) included a base model structure that contained variables supported during a first stage of analysis (Year + Age). Year $=$ fixed effect of study year $(2014,2015,2016)$; Age = Hatch Year vs After Hatch Year; Date of Capture $=$ the ordinal date of year that the bird was captured; Sex $=$ Male vs Female; Study Area = survival allowed to vary among two study areas. $\mathrm{LN}$ (Day) reflects a natural log transformation of the number of days postcapture.

deviance (Fig. 1), and among all threshold models had an $\mathrm{AIC}_{\mathrm{c}}$ weight $\left(w_{i}=0.55\right)$ that was $3.5 \mathrm{x}$ greater than the day 10 model $\left(w_{i}\right.$ $=0.15$ ). When averaged across years and age classes, this model suggested the mean daily survival probability during the first six days following release was $0.980( \pm 0.003 \mathrm{SE})$, and for days 7 through 30 the mean daily survival was 0.997 ( $\pm 0.001 \mathrm{SE})$.
Fig. 1. Daily survival probabilities (A) and model deviance (B) from analysis of radio-marked Ruffed Grouse (Bonasa umbellus) survival during the first 30 days following release. For panel A, point estimates of daily survival (error bars reflect 95\% confidence intervals) were derived from a model allowing full independence among daily estimates. The solid line reflects a quadric trend in daily survival, and the dashed line represents a model that identified a threshold in mortality that occurred between days 6 and 7. Panel B represent differences in model deviance among all potential daily thresholds for postrelease mortality. The y-axis is inverted, and smaller deviance values indicate better fit, where the best-fit model is indicated by the dashed vertical line. All models were ran as nest survival analyses, implemented in Program MARK (White and Burnham 1999) using the R package RMark (Laake 2016).
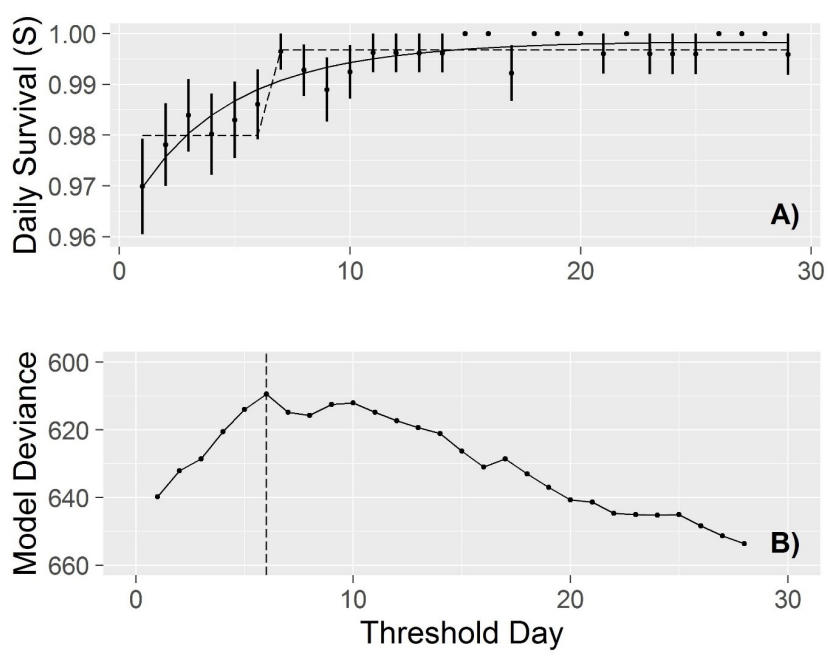

However, models that included linear trends, quadratic trends, and a natural log transformation of day were better-supported than the most competitive threshold model, with the greatest support for the quadratic trend (Table 1).

When comparing trend-and threshold-based estimates with those from a model that allowed for independent estimates across the entire 30-day postrelease period, it was apparent that support for the quadratic trend was driven in large part by a systematic increase in survival during the first six days postrelease, where survival was lowest during the first 24 hours and increased progressively thereafter (Fig. 1). The six-day threshold model explained approximately $65 \%$ of the temporal variance in postrelease survival $\left(R_{-}^{2} D e v=0.65\right)$, and the quadratic daily trend model explained an additional $9 \%\left(R^{2} \_\right.$Dev $\left.=0.74\right)$.

\section{DISCUSSION}

We found that approaches to addressing capture effects differed among investigators. Although our review allowed us to quantify standard practices, there were additional differences that were more subtle and difficult to characterize with a formal review. The majority of researchers applied some sort of a censoring protocol to account for capture-related mortality, however specific strategies used, and whether censoring was employed at all, varied 
somewhat among species. For example, 9 of 14 studies that we reviewed on Greater Sage-Grouse (Centrocercus urophasianus) reported no censoring criteria, and those that did were often focused on radio-marked chicks and censored individuals based on field evidence that suggested capture effects (Gregg and Crawford 2009, Dahlgren et al. 2010, Guttery et al. 2013). In contrast, all five studies of Wild Turkeys (Meleagris gallopavo) reported some explicit form of censoring (Table A1.1). Censoring was also more often applied for species that were commonly captured using wire traps or rocket nets, and also for studies focused on newly hatched chicks, whereas species commonly captured using other methods, e.g., nighttime spotlighting, were less likely to be censored. These apparent differences may reflect researcher perception of the relative risk posed to birds by each capture method. Variable field practices among researchers, or different conditions among study systems, could result in a true difference in capture effects among studies, even for the same species observed using conventional methods. We therefore suggest that researchers use a systematic approach for detecting capture effects and mortality thresholds, which may ultimately be the best way to standardize results among studies and investigators.

In our case study of Ruffed Grouse, we found that mortality associated with capture persisted at least six days following release of the bird. The field methods we used for our study mirrored previous work on Ruffed Grouse (e.g., Devers et al. 2007, Skrip et al. 2011), and a six-day threshold aligns very closely with that used in Ruffed Grouse research (typically seven days; Small et al. 1991, Yoder et al. 2004, Devers et al. 2007, Skrip et al. 2011). The daily survival probabilities from our study suggest the mortality rate prior to day $7\left(1-S^{6}=0.117\right)$ approximated the proportion of Ruffed Grouse that Small et al. (1991) reported dying during the first seven days postrelease (12.1\% of 461 radio-marked Ruffed Grouse; Small et al. 1991). We also found that mortality during the first six days postrelease was reduced substantially during our second two field seasons compared to the first. Although this difference could be attributed to a number of environmental factors we did not measure, e.g., changes in predator density, it also coincided with changes to our field protocols designed to reduce stress and injury during capture. Schumacher (2002) similarly suggested that checking traps twice each day reduced rates of self-inflicted injury for Ruffed Grouse in North Carolina, but also noted a trade-off between more frequent trap checks and the total number of traps that could be monitored (and thus total capture success). We suggest that investigators adopt bidaily trap checks, and add concealment to both the top and sides of trap bodies, as standard protocols when using lily-pad traps (Gullion 1965) to capture Ruffed Grouse. These modifications may also help to shorten censorship times, which would benefit researchers by allowing a larger number of birds to contribute data.

The method we used to detect postrelease thresholds of mortality is easily implemented and widely applicable to other studies of radio-marked birds, and a number of previous studies have used similar approaches. Holt et al. (2009) evaluated thresholds at 1, 2, 3, 7, 14, and 21 days for Northern Bobwhite, and found no evidence for time-effects on postrelease survival. Working with translocated Wild Turkeys, Kane et al. (2007) evaluated staggered entry at $7,14,21$, and 28 day intervals, and chose seven days as the most appropriate threshold based largely on qualitative differences in the number of mortalities observed during each interval. Our approach builds on these earlier works by modeling all possible dates within one month postrelease, thus providing an assessment of postrelease mortality thresholds across a continuous time scale and allowing for a more precise determination of the optimal threshold value. This is important because of the inherent trade-off between positive and negative bias when left-censoring individuals from a survival history; being too conservative results in unnecessary censorship of individuals that died for reasons not related to capture (positive bias), whereas being too liberal risks including mortalities related to capture (negative bias). By choosing the best-supported threshold from among all possible dates, this trade-off should, in theory, be optimized. A similar approach was used by Mathews et al. (2016) when evaluating thresholds for translocation effects in Sharptailed Grouse (Tympanuchus phasianellus), although in this case the authors used time periods that were binned into 10-day intervals and that extended to 150 days postrelease. Because the authors' central research question was related to translocation, and not capture effects per se, their use of a longer history and coarser time intervals were justified. We acknowledge that evaluating all possible date thresholds results in a relatively large number of models. Researchers could limit the total number of model comparisons by first examining estimates from models that allow full daily variation in survival, and use those results to inform construction of a subset of models within a more restricted date range.

Future studies of avian survival based on radio telemetry would likely benefit from more consistent evaluation of short-term effects of capture effects on survival, but this may not be necessary in all cases. For example, death of radio-marked individuals shortly following capture may be rare for species with high intrinsic rates of survival or where capture methods are less invasive. In such cases accounting for capture effects on mortality may be unnecessary, although nonlethal effects of capture may also persist in these situations (e.g., Cattet et al. 2008). In situations where radio-marked individuals do die within the first few weeks following capture, a systematic approach to detecting shifts in mortality offers an empirically justified tool to identify thresholds for censorship. We suggest that researchers focus on relatively short intervals, e.g., 1 month, and fine resolution, e.g., daily, data to best match the temporal scale at which these processes likely operate. Use of an empirical approach allows researchers to better account for capture-related impacts to survival while also limiting unnecessary censorship of birds whose deaths were more likely to be independent of capture. Formally addressing capture effects as a side objective can also help to elucidate modifications to field methods that reduce stress and injury to captured birds, thus improving animal welfare (e.g., Grisham et al. 2015).

Responses to this article can be read online at: http://www.ace-eco.org/issues/responses.php/1147

\section{Acknowledgments:}

We thank the numerous field technicians, volunteers, and staff members that assisted with Ruffed Grouse capture and handling. Land access was granted by the Maine Department of Inland 
Fisheries and Wildlife, American Forest Management, Maine Field Office of the Nature Conservancy, and Wells Forest. B. Allen provided helpful comments on an earlier draft of the manuscript. This research was funded by the Maine Agricultural and Forest Experiment Station, the Federal Aid in Wildlife Restoration Act, and the Maine Department of Inland Fisheries and Wildlife. This project was supported by the USDA National Institute of Food and Agriculture, Hatch (or McIntire-Stennis, Animal Health, etc.) project number \#ME021422 and \#ME041602 through the Maine Agricultural \& Forest Experiment Station. This is Maine Agricultural and Forest Experiment Station Publication Number 3577.

\section{LITERATURE CITED}

Anderson, D. R., and K. P. Burnham. 2002. Model selection and multi-model inference: a practical information-theoretic approach. Second edition. Springer-Verlag, New York, New York, USA.

Arnemo, J. M., P. Ahlqvist, R. Andersen, F. Berntsen, G. Ericsson, J. Odden, S. Brunberg, P. Segerström, and J. E. Swenson. 2006. Risk of capture-related mortality in large free-ranging mammals: experiences from Scandinavia. Wildlife Biology 12:109-113. http:// dx.doi.org/10.2981/0909-6396(2006)12[109:ROCMIL]2.0.CO;2

Barron, D. G., J. D. Brawn, and P. J. Weatherhead. 2010. Metaanalysis of transmitter effects on avian behaviour and ecology. Methods in Ecology and Evolution 1:180-187. http://dx.doi. org/10.1111/j.2041-210X.2010.00013.x

Calvo, B., and R. W. Furness. 1992. A review of the use and the effects of marks and devices on birds. Ringing \& Migration 13:129-151. http://dx.doi.org/10.1080/03078698.1992.9674036

Cattet, M., J. Boulanger, G. Stenhouse, R. A. Powell, and M. J. Reynolds-Hogland. 2008. An evaluation of long-term capture effects in Ursids: implications for wildlife welfare and research. Journal of Mammalogy 89:973-990. http://dx.doi.org/10.1644/08MAMM-A-095.1

Dahlgren, D. K., T. A. Messmer, and D. N. Koons. 2010. Achieving better estimates of Greater Sage-Grouse chick survival in Utah. Journal of Wildlife Management 74:1286-1294. http://dx. doi.org/10.1111/j.1937-2817.2010.tb01249.x

Davis, J. A. 1969. Aging and sexing criteria for Ohio Ruffed Grouse. Journal of Wildlife Management 33:628-636. http://dx. doi.org/10.2307/3799387

Davis, S. B. 2017. Survival, harvest, and drumming ecology of Ruffed Grouse in central Maine, USA. Thesis. University of Maine, Orono, Maine, USA.

Devers, P. K., D. F. Stauffer, G. W. Norman, D. E. Steffen, D. M. Whitaker, J. D. Sole, T. J. Allen, S. L. Bittner, D. A. Buehler, J. W. Edwards, D. E. Figert, S. T. Friedhoff, W. W. Giuliano, C. A. Harper, W. K. Igo, R. L. Kirkpatrick, M. H. Seamster, H. A. Spiker, D. A. Swanson, and B. C. Tefft. 2007. Ruffed Grouse population ecology in the Appalachian region. Wildlife Monographs 168:1-36. http://dx.doi.org/10.2193/0084-0173.168

Dugger, K. M., G. Ballard, D. G. Ainley, and K. J. Barton. 2006. Effects of flipper bands on foraging behavior and survival of Adélie Penguins (Pygoscelis adeliae). Auk 123:858-869. http://dx. doi.org/10.1642/0004-8038(2006)123[858:EOFBOF]2.0.CO;2
Esler, D., D. M. Mulcahy, and R. L. Jarvis. 2000. Testing assumptions for unbiased estimation of survival of radiomarked Harlequin Ducks. Journal of Wildlife Management 64:591-598. http://dx.doi.org/10.2307/3803257

Fremgen, M. R., D. Gibson, R. L. Ehlrich, A. H. Krakauer, J. S. Forbey, E. J. Blomberg, J. S. Sedinger, and G. L. Patricelli. 2017. Necklace-style radio-transmitters are associated with changes in display vocalizations of male Greater Sage-Grouse. Wildlife Biology. http://dx.doi.org/10.2981/wlb.00236

Gibson, D., E. J. Blomberg, G. L. Patricelli, A. H. Krakauer, M. T. Atamian, and J. S. Sedinger. 2013. Effects of radio collars on survival and lekking behavior of male Greater Sage-Grouse Condor 115:769-776. http://dx.doi.org/10.1525/cond.2013.120176

Gregg, M. A., and J. A. Crawford. 2009. Survival of Greater SageGrouse chicks and broods in the Northern Great Basin. Journal of Wildife Management 73:904-913. http://dx.doi.org/10.2193/2007-410

Grisham, B. A., C. W. Boal, N. R. Mitchell, T. S. Gicklhorn, P. K. Borsdorf, D. A. Haukos, and C. E. Dixon. 2015. Evaluation of capture techniques on Lesser Prairie-Chicken trap injury and survival. Journal of Fish and Wildlife Management 6:318-326. http://dx.doi.org/10.3996/032015-JFWM-022

Grosbois, V., O. Gimenez, J.-M. Gaillard, R. Pradel, C. Barbraud, J. Clobert, A. P. Møller, and H. Weimerskirch. 2008. Assessing the impact of climate variation on survival in vertebrate populations. Biological Reviews 83:357-399. http://dx.doi. org/10.1111/j.1469-185X.2008.00047.x

Gullion, G. W. 1965. Improvements in methods for trapping and marking Ruffed Grouse. Journal of Wildlife Management 29:109-116. http://dx.doi.org/10.2307/3798639

Gutierrez, R. J., G. S. Zimmerman, and G. W. Gullion. 2003. Daily survival rates of Ruffed Grouse Bonasa umbellus in northern Minnesota. Wildlife Biology 9:351-356.

Guttery, M. R., D. K. Dahlgren, T. A. Messmer, J. W. Connelly, K. P. Reese, P. A. Terletzky, N. Burkepile, and D. N. Koons. 2013. Effects of landscape-scale environmental variation on Greater Sage-Grouse chick survival. PLoS ONE 8:e65582. http://dx.doi. org/10.1371/journal.pone.0065582

Hagen, C. A., B. K. Sandercock, J. C. Pitman, R. J. Robel, and R. D. Applegate. 2006. Radiotelemetry survival estimates of Lesser Prairie-Chickens in Kansas: Are there transmitter biases? Wildlife Society Bulletin 34:1064-1069. http://dx.doi.org/10.2193/0091-7648 (2006)34[1064:RSEOLP]2.0.CO;2

Holt, R. D., L. W. Burger, S. J. Dinsmore, M. D. Smith, S. J. Szukaitis, and K. D. Godwin. 2009. Estimating duration of shortterm acute effects of capture handling and radiomarking. Journal of Wildlife Management 73:989-995. http://dx.doi.org/10.2193/2008-073

Kane, D. F., R. O. Kimmel, and W. E. Faber. 2007. Winter survival of Wild Turkey females in central Minnesota. Journal of Wildlife Management 71:1800-1807. http://dx.doi.org/10.2193/2006-008

Laake, J. 2016. Package "RMark": R code for Mark analysis. R Package Version 2.2.2.

Mathews, S. R., P. S. Coates, and D. J. Delehanty. 2016. Survival of translocated Sharp-tailed Grouse: temporal threshold and age effects. Wildlife Research 43:220-227. http://dx.doi.org/10.1071/ WR 15158 
Murray, D. L. 2006. On improving telemetry-based survival estimation. Journal of Wildlife Management 70:1530-1543. http:// dx.doi.org/10.2193/0022-541X(2006)70[1530:OITSE]2.0.CO;2

Murray, D. L., and M. R. Fuller. 2000. A critical review of the effects of marking on the biology of vertebrates. Pages 15-46 in L. Boitani and T. Fuller, editors. Research techniques in animal ecology: controversies and consequences. Columbia University Press, New York, New York, USA.

Murray, D. L., and B. R. Patterson. 2006. Wildlife survival estimation: recent advances and future directions. Journal of Wildlife Management 70:1499-1503. http://dx.doi.org/10.2193/0022-541X (2006)70[1499:WSERAA]2.0.CO;2

Pollock, K. H., and D. G. Raveling. 1982. Assumptions of modern band-recovery models, with emphasis on heterogeneous survival rates. Journal of Wildlife Management 46:88-98. http://dx.doi. org/10.2307/3808411

R Core Team. 2017. R: A language and environment for statistical computing. R Foundation for Statistical Computing, Vienna, Austria.

Sandercock, B. K. 2006. Estimation of demographic parameters from live-encounter data: a summary review. Journal of Wildlife Management 70:1504-1520. http://dx.doi.org/10.2193/0022-541X (2006)70[1504:EODPFL]2.0.CO;2

Schumacher, C. 2002. Ruffed Grouse habitat use in western North Carolina. Thesis. University of Tennessee, Knoxville, Tennessee, USA.

Skrip, M. M., W. F. Porter, B. L. Swift, and M. V. Schiavone. 2011. Fall-winter survival of Ruffed Grouse in New York State. Northeastern Naturalist 18:395-410. http://dx.doi. org/10.1656/045.018.0401

Small, R. J., J. C. Holzwart, and D. H. Rusch. 1991. Predation and hunting mortality of Ruffed Grouse in central Wisconsin. Journal of Wildlife Management 55:512-520. http://dx.doi. org/10.2307/3808983

White, G. C., and K. P. Burnham. 1999. Program MARK: survival estimation from populations of marked animals. Bird Study 46: S120-S139. http://dx.doi.org/10.1080/00063659909477239

Yoder, J. M., E. A. Marshall, and D. A. Swanson. 2004. The cost of dispersal: predation as a function of movement and site familiarity in Ruffed Grouse. Behavioral Ecology 15:469-476. http://dx.doi.org/10.1093/beheco/arh037 


\section{Appendix 1. Summary of literature review on current practices for censoring capture- related mortalities in upland game birds.}

Table A1.1. Sources and information obtained during literature review to document researcher strategies for addressing capture-related mortality following release of radio-marked upland game birds from 2006 to 2016.

\begin{tabular}{|c|c|c|c|c|}
\hline Source & Species & Method $^{\dagger}$ & $\begin{array}{l}\text { Censor } \\
\text { Period } \\
\text { (Days) } \\
\end{array}$ & $\begin{array}{c}\text { Prop. } \\
\text { Censored }\end{array}$ \\
\hline Devers et al. 2007 & Bonasa umbellus & Delayed history & 7 & - \\
\hline Skrip et al. 2011 & Bonasa umbellus & Arbitrary & 7 & - \\
\hline Anthony and Willis 2009 & Centrocercus urophasianus & Did not censor & - & - \\
\hline Baxter et al. 2008 & Centrocercus urophasianus & Did not censor & - & - \\
\hline Beck et al. 2006 & Centrocercus urophasianus & Did not censor & - & - \\
\hline Blomberg et al. 2013b & Centrocercus urophasianus & Did not censor & - & - \\
\hline Blomberg et al. 2013a & Centrocercus urophasianus & Did not censor & - & - \\
\hline Blomberg et al. 2014 & Centrocercus urophasianus & Did not censor & - & - \\
\hline Caudill et al. 2014 & Centrocercus urophasianus & Systematic & 0 & - \\
\hline Dahlgren et al. 2010 & Centrocercus urophasianus & Cause of death & - & - \\
\hline Gibson et al. 2013 & Centrocercus urophasianus & Did not censor & - & - \\
\hline Gregg et al. 2007 & Centrocercus urophasianus & Did not censor & - & - \\
\hline Gregg and Crawford 2009 & Centrocercus urophasianus & Cause of death & 1 & 0.06 \\
\hline Guttery et al. 2013 & Centrocercus urophasianus & Cause of death & - & - \\
\hline Holloran et al. 2010 & Centrocercus urophasianus & Did not censor & - & - \\
\hline Moynahan et al. 2006 & Centrocercus urophasianus & Arbitrary & 4 & - \\
\hline Buckley et al. 2015 & Colinus virginianus & Arbitrary & 7 & - \\
\hline DeMaso et al. 2014 & Colinus virginianus & Arbitrary & 14 & - \\
\hline Holt et al. 2012 & Colinus virginianus & Did not censor & - & - \\
\hline Holt et al. 2009 & Colinus virginianus & Systematic & 0 & - \\
\hline Janke and Gates 2012 & Colinus virginianus & Arbitrary & 7 & 0.02 \\
\hline Janke et al. 2015 & Colinus virginianus & Delayed history & 7 & - \\
\hline Lohr et al. 2011 & Colinus virginianus & Arbitrary & 7 & 0.04 \\
\hline Palmer and Wellendorf 2007 & Colinus virginianus & Did not censor & - & - \\
\hline Peters et al. 2015 & Colinus virginianus & Delayed history & 7 & 0.06 \\
\hline Rolland et al. 2010 & Colinus virginianus & Did not censor & - & - \\
\hline Scott et al. 2013 & Colinus virginianus & Arbitrary & 14 & - \\
\hline Seckinger et al. 2008 & Colinus virginianus & Did not censor & - & - \\
\hline Sisson et al. 2006 & Colinus virginianus & Arbitrary & 7 & 0.02 \\
\hline Tanner et al. 2012 & Colinus virginianus & Did not censor & - & - \\
\hline Terhune et al. 2007 & Colinus virginianus & Did not censor & - & - \\
\hline Terhune et al. 2010 & Colinus virginianus & Did not censor & - & - \\
\hline Unger et al. 2012 & Colinus virginianus & Did not censor & - & - \\
\hline West et al. 2012 & Colinus virginianus & Did not censor & - & - \\
\hline
\end{tabular}


Anich et al. 2013

Sandercock et al. 2011

Bowker et al. 2007

Pekkola et al. 2014

Collier et al. 2007

Collier et al. 2009

Holdstock et al. 2006

Humberg et al. 2009

Kane et al. 2007

Stephenson et al. 2011

Troy et al. 2013

Venturato et al. 2009

Augustine and Sandercock 2011

Winder et al. 2014

Carrlson et al. 2014

Grisham and Boal 2015

Grisham et al. 2015

Hagen et al. 2006

Hagen et al. 2007

Lyons et al. 2009

Pirius et al. 2013

Pitman et al. 2006

Pitman et al. 2006

Manzer and Hannon 2008

Manzer and Hannon 2008

Mathews et al. 2016
Faclipennis canadensis

Lagopus lagopus

Lyrurus tetrix

Lyrurus tetrix

Meleagris gallopavo

Meleagris gallopavo

Meleagris gallopavo

Meleagris gallopavo

Meleagris gallopavo

Oreortyx pictus

Oreortyx pictus

Phasianus colchicus

Tympanuchus cupido

Tympanuchus cupido

Tympanuchus pallidicinctus

Tympanuchus pallidicinctus

Tympanuchus pallidicinctus

Tympanuchus pallidicinctus

Tympanuchus pallidicinctus

Tympanuchus pallidicinctus

Tympanuchus pallidicinctus

Tympanuchus pallidicinctus

Tympanuchus pallidicinctus

Tympanuchus phasuanellus

Tympanuchus phasuanellus

Tympanuchus phasuanellus
Did not censor

Did not censor

Arbitrary

14

Did not censor

Arbitrary

21

Delayed history

Arbitrary

Arbitrary

Systematic

Did not censor

Delayed history

Systematic

Did not censor

Arbitrary

Did not censor

Arbitrary

Delayed history

Did not censor

Arbitrary

Arbitrary

Did not censor

Cause of death

Arbitrary

Cause of death

Did not censor

Systematic

$\dagger^{\dagger}$ Arbitrary - birds that die prior to a specified date are removed from the sample, timing of censorship not analytically-informed; Cause of Death - individuals are censored from the history based on evidence that suggest capture- or transmitter-related death; Delayed history - all birds enter the survival history following a specified censoring period; Did not censor - No censoring was applied or it was not reported in the paper; Systematic - some form of analytical approach was used to determine the most appropriate censorship date

$\$$ The proportion of the total sample of marked birds that were reported as censored following release due to capture-related mortality.

\section{LITERATURE CITED}

Anich, N. M., M. Worland, and K. J. Martin. 2013. Nest-site selection, nest survival, productivity, and survival of Spruce Grouse in Wisconsin. The Wilson Journal of 
Ornithology 125:570-582. doi: 10.1676/12-168.1.

Anthony, R. G., and M. J. Willis. 2009. Survival Rates of Female Greater Sage-Grouse in Autumn and Winter in Southeastern Oregon. Journal of Wildlife Management 73:538545. doi: 10.2193/2008-177.

Augustine, J. K., and B. K. Sandercock. 2011. Demography of Female Greater Prairie-Chickens in Unfragmented Grasslands in Kansas. Avian Conservation and Ecology 6. doi: 10.5751/ACE-00429-060102.

Baxter, R. J., J. T. Flinders, and D. L. Mitchell. 2008. Survival, Movements, and Reproduction of Translocated Greater Sage-Grouse in Strawberry Valley, Utah. Journal of Wildlife Management 72:179-186. doi: 10.2193/2006-402.

Beck, J. L., K. P. Reese, J. W. Connelly, and M. B. Lucia. 2006. Movements and Survival of Juvenile Greater Sage-Grouse in Southeastern Idaho. Wildlife Society Bulletin 34:10701078. doi: 10.2193/0091-7648(2006)34[1070:MASOJG]2.0.CO;2.

Blomberg, E. J., D. Gibson, J. S. Sedinger, M. L. Casazza, and P. S. Coates. 2013a. Intraseasonal variation in survival and probable causes of mortality in greater sage-grouse Centrocercus urophasianus. Wildlife Biology 19:347-357. doi: 10.2981/13-001.

Blomberg, E. J., J. S. Sedinger, D. Gibson, P. S. Coates, and M. L. Casazza. 2014. Carryover effects and climatic conditions influence the postfledging survival of greater sage-grouse. Ecology and Evolution 4:4488-4499. doi: 10.1002/ece3.1139.

Blomberg, E. J., J. S. Sedinger, D. V. Nonne, and M. T. Atamian. 2013b. Seasonal reproductive costs contribute to reduced survival of female greater sage-grouse. Journal of Avian Biology 44:149-158. doi: 10.1111/j.1600-048X.2012.00013.x.

Bowker, G., C. Bowker, and D. Baines. 2007. Survival Rates and Causes of Mortality in Black 
Grouse Tetrao Tetrix at Lake Vyrnwy, North Wales, UK. Wildlife Biology 13:231-237. doi: 10.2981/0909-6396(2007)13[231:SRACOM]2.0.CO;2.

Buckley, B. R., A. K. Andes, B. A. Grisham, and C. Brad Dabbert. 2015. Effects of broadcasting supplemental feed into roadside vegetation on home range and survival of female northern bobwhite: Roadside Supplemental Feeding For Bobwhite. Wildlife Society Bulletin 39:301-309. doi: 10.1002/wsb.533.

Carrlson, K. M., D. C. Kesler, and T. R. Thompson. 2014. Survival and habitat use in translocated and resident greater prairie-chickens. Journal for Nature Conservation 22:405-412. doi: 10.1016/j.jnc.2014.03.008.

Caudill, D., T. A. Messmer, B. Bibles, and M. R. Guttery. 2014. Greater sage-grouse juvenile survival in Utah: Greater Sage-Grouse Juvenile Survival. The Journal of Wildlife Management 78:808-817. doi: 10.1002/jwmg.724.

Collier, B. A., D. A. Jones, J. N. Schaap, C. J. Randel, B. J. Willsey, R. Aguirre, T. W. Schwertner, N. J. Silvy, and M. J. Peterson. 2007. Survival of Rio Grande Wild Turkeys on the Edwards Plateau of Texas. Journal of Wildlife Management 71:82-86. doi: $10.2193 / 2005-751$.

Collier, B. A., K. B. Melton, J. B. Hardin, N. J. Silvy, and M. J. Peterson. 2009. Impact of Reproductive Effort on Survival of Rio Grande Wild Turkey Meleagris Gallop Intermedia Hens in Texas. Wildlife Biology 15:370-379. doi: 10.2981/09-011.

Dahlgren, D. K., T. A. Messmer, and D. N. Koons. 2010. Achieving Better Estimates of Greater Sage-Grouse Chick Survival in Utah. Journal of Wildlife Management 74:1286-1294. doi: 10.2193/2009-093.

DeMaso, S. J., F. Hernández, L. A. Brennan, N. J. Silvy, W. E. Grant, X. Ben Wu, and F. C. 
Bryant. 2014. Short- and Long-Term Influence of Brush Canopy Cover on Northern Bobwhite Demography in Southern Texas. Rangeland Ecology \& Management 67:99_ 106. doi: 10.2111/REM-D-13-00094.1.

Devers, P. K., D. F. Stauffer, G. W. Norman, D. E. Steffen, D. M. Whitaker, J. D. Sole, T. J. Allen, S. L. Bittner, D. A. Buehler, J. W. Edwards, D. E. Figert, S. T. Friedhoff, W. W. Giuliano, C. A. Harper, W. K. Igo, R. L. Kirkpatrick, M. H. Seamster, H. A. Spiker, D. A. Swanson, and B. C. Tefft. 2007. Ruffed Grouse Population Ecology in the Appalachian Region. Wildlife Monographs 168:1-36. doi: 10.2193/0084-0173.168.

Gibson, D., E. J. Blomberg, G. L. Patricelli, A. H. Krakauer, M. T. Atamian, and J. S. Sedinger. 2013. Effects of Radio Collars on Survival and Lekking Behavior of Male Greater SageGrouse. The Condor 115:769-776. doi: 10.1525/cond.2013.120176.

Gregg, M. A., and J. A. Crawford. 2009. Survival of Greater Sage-Grouse Chicks and Broods in the Northern Great Basin. Journal of Wildlife Management 73:904-913. doi: 10.2193/2007-410.

Gregg, M. A., M. R. Dunbar, and J. A. Crawford. 2007. Use of Implanted Radiotransmitters to Estimate Survival of Greater Sage-Grouse Chicks. Journal of Wildlife Management 71:646-651. doi: 10.2193/2006-353.

Grisham, B. A., and C. W. Boal. 2015. Causes of mortality and temporal patterns in breeding season survival of lesser prairie-chickens in shinnery oak prairies: Lesser Prairie-Chicken Survival and Mortality. Wildlife Society Bulletin 39:536-542. doi: 10.1002/wsb.551.

Grisham, B. A., C. W. Boal, N. R. Mitchell, T. S. Gicklhorn, P. K. Borsdorf, D. A. Haukos, and C. E. Dixon. 2015. Evaluation of Capture Techniques on Lesser Prairie-Chicken Trap Injury and Survival. Journal of Fish and Wildlife Management 6:318-326. doi: 
10.3996/032015-JFWM-022.

Guttery, M. R., D. K. Dahlgren, T. A. Messmer, J. W. Connelly, K. P. Reese, P. A. Terletzky, N. Burkepile, and D. N. Koons. 2013. Effects of Landscape-Scale Environmental Variation on Greater Sage-Grouse Chick Survival. PLoS ONE 8:e65582. doi:

10.1371/journal.pone.0065582.

Hagen, C. A., J. C. Pitman, B. K. Sandercock, R. J. Robel, and R. D. Applegate. 2007. AgeSpecific Survival and Probable Causes of Mortality in Female Lesser Prairie-Chickens. Journal of Wildlife Management 71:518-525. doi: 10.2193/2005-778.

Hagen, C. A., B. K. Sandercock, J. C. Pitman, R. J. Robel, and R. D. Applegate. 2006. Radiotelemetry Survival Estimates of Lesser Prairie-Chickens in Kansas: Are There Transmitter Biases? Wildlife Society Bulletin 34:1064-1069. doi: 10.2193/00917648(2006)34[1064:RSEOLP]2.0.CO;2.

Holdstock, D. P., M. C. Wallace, W. B. Ballard, J. H. Brunjes, R. S. Phillips, B. L. Spears, S. J. Demaso, J. D. Jernigan, R. D. Applegate, and P. S. Gipson. 2006. Male Rio Grande Turkey Survival and Movements in the Texas Panhandle and Southwestern Kansas. Journal of Wildlife Management 70:904-913. doi: 10.2193/0022541X(2006)70[904:MRGTSA]2.0.CO;2.

Holloran, M. J., R. C. Kaiser, and W. A. Hubert. 2010. Yearling Greater Sage-Grouse Response to Energy Development in Wyoming. Journal of Wildlife Management 74:65-72. doi: $10.2193 / 2008-291$.

Holt, R. D., L. Burger Jr, B. D. Leopold, and K. D. Godwin. 2012. Annual variation in northern bobwhite survival and raptor migration.

Holt, R. D., L. W. Burger, S. J. Dinsmore, M. D. Smith, S. J. Szukaitis, and K. D. Godwin. 2009. 
Estimating Duration of Short-Term Acute Effects of Capture Handling and Radiomarking. Journal of Wildlife Management 73:989-995. doi: 10.2193/2008-073.

Humberg, L. A., T. L. Devault, and O. E. Rhodes. 2009. Survival and Cause-Specific Mortality of Wild Turkeys in Northern Indiana. The American Midland Naturalist 161:313-322. doi: 10.1674/0003-0031-161.2.313.

Janke, A. K., and R. J. Gates. 2012. Temporal variability in survival of non-breeding Northern Bobwhites in Ohio.

Janke, A. K., R. J. Gates, and T. M. Terhune II. 2015. Habitat influences Northern Bobwhite survival at fine spatiotemporal scales. The Condor 117:41-52. doi: 10.1650/CONDOR14-115.1.

Kane, D. F., R. O. Kimmel, and W. E. Faber. 2007. Winter Survival of Wild Turkey Females in Central Minnesota. Journal of Wildlife Management 71:1800-1807. doi: 10.2193/2006008.

Lohr, M., B. M. Collins, C. K. Williams, and P. M. Castelli. 2011. Life on the edge: Northern bobwhite ecology at the northern periphery of their range. The Journal of Wildlife Management 75:52-60. doi: 10.1002/jwmg.25.

Lyons, E. K., B. A. Collier, N. J. Silvy, R. R. Lopez, B. E. Toole, R. S. Jones, and S. J. DeMaso. 2009. Breeding and Non-Breeding Survival of Lesser Prairie-Chickens Tympanuchus pallidicinctus in Texas, USA. Wildlife Biology 15:89-96. doi: 10.2981/07-083.

Manzer, D. L., and S. J. Hannon. 2008. Survival of sharp-tailed grouse Tympanuchus phasianellus chicks and hens in a fragmented prairie landscape. Wildlife Biology 14:1625. doi: 10.2981/0909-6396(2008)14[16:SOSGTP]2.0.CO;2.

Mathews, S. R., P. S. Coates, and D. J. Delehanty. 2016. Survival of translocated sharp-tailed 
grouse: temporal threshold and age effects. Wildlife Research 43:220. doi: 10.1071/WR15158.

Moynahan, B. J., M. S. Lindberg, and J. W. Thomas. 2006. Factors Contributing to Process Variance in Annual Survival of Female Greater Sage-Grouse in Montana. Ecological Applications 16:1529-1538. doi: 10.1890/1051-0761(2006)016[1529:FCTPVI]2.0.CO;2.

Palmer, W. E., and S. D. Wellendorf. 2007. Effect of Radiotransmitters on Northern Bobwhite Annual Survival. Journal of Wildlife Management 71:1281-1287. doi: 10.2193/2005639.

Pekkola, M., R. Alatalo, H. Pöysä, and H. Siitari. 2014. Seasonal survival of young and adult black grouse females in boreal forests. European Journal of Wildlife Research 60:477488. doi: 10.1007/s10344-014-0809-0.

Peters, D. C., J. M. Brooke, E. P. Tanner, A. M. Unger, P. D. Keyser, C. A. Harper, J. D. Clark, and J. J. Morgan. 2015. Impact of experimental habitat manipulation on northern bobwhite survival: Habitat Manipulation and Bobwhite Survival. The Journal of Wildlife Management 79:605-617. doi: 10.1002/jwmg.873.

Pirius, N. E., C. W. Boal, D. A. Haukos, and M. C. Wallace. 2013. Winter habitat use and survival of lesser prairie-chickens in West Texas: Prairie-Chicken Habitat Use and Survival. Wildlife Society Bulletin 37:759-765. doi: 10.1002/wsb.354.

Pitman, J. C., C. A. Hagen, B. E. Jamison, R. J. Robel, T. M. Loughin, and R. D. Applegate. 2006. Survival of Juvenile Lesser Prairie-Chickens in Kansas. Wildlife Society Bulletin 34:675-681. doi: 10.2193/0091-7648(2006)34[675:SOJLPI]2.0.CO;2.

Rolland, V., J. A. Hostetler, T. C. Hines, H. F. Percival, and M. K. Oli. 2010. Impact of harvest on survival of a heavily hunted game bird population. Wildlife Research 37:392. doi: 
10.1071/WR09177.

Sandercock, B. K., E. B. Nilsen, H. Brøseth, and H. C. Pedersen. 2011. Is hunting mortality additive or compensatory to natural mortality? Effects of experimental harvest on the survival and cause-specific mortality of willow ptarmigan: Harvest and ptarmigan survival. Journal of Animal Ecology 80:244-258. doi: 10.1111/j.13652656.2010.01769.x.

Scott, J. L., F. Hernández, L. A. Brennan, B. M. Ballard, M. Janis, and N. D. Forrester. 2013. Population demographics of translocated northern bobwhites on fragmented habitat. Wildlife Society Bulletin 37:168-176. doi: 10.1002/wsb.239.

Sisson, D. C., T. M. Terhune II, and H. L. Stribling. 2006. Additional evidence against radiohandicapping of northern bobwhites. Page Gamebird 2006: A joint conference of Quail VI and Perdix XII. D. B. Warnell School of Forestry and Natural Resources.

Skrip, M. M., W. F. Porter, B. L. Swift, and M. V. Schiavone. 2011. Fall-Winter Survival of Ruffed Grouse in New York State. Northeastern Naturalist 18:395-410. doi: 10.1656/045.018.0401.

Stephenson, J. A., K. P. Reese, P. Zager, P. E. Heekin, P. J. Nelle, and A. Martens. 2011. Factors influencing survival of native and translocated mountain quail in Idaho and Washington. The Journal of Wildlife Management 75:1315-1323. doi: 10.1002/jwmg.189.

Tanner, E. P., A. M. Unger, P. D. Keyser, C. A. Harper, J. D. Clark, and J. J. Morgan. 2012. Survival of radio-marked versus leg-banded northern bobwhite in Kentucky.

Terhune, T. M., D. C. Sisson, J. B. Grand, and H. L. Stribling. 2007. Factors Influencing Survival of Radiotagged and Banded Northern Bobwhites in Georgia. Journal of Wildlife Management 71:1288-1297. doi: 10.2193/2005-640. 
Terhune, T. M., D. C. Sisson, W. E. Palmer, B. C. Faircloth, H. L. Stribling, and J. P. Carroll. 2010. Translocation to a fragmented landscape: survival, movement, and site fidelity of northern bobwhites. Ecological Applications 20:1040-1052.

Troy, R. J., P. S. Coates, J. W. Connelly, G. Gillette, and D. J. Delehanty. 2013. Survival of mountain quail translocated from two distinct source populations: Survival of Translocated Mountain Quail. The Journal of Wildlife Management 77:1031-1037. doi: 10.1002/jwmg.549.

Unger, A. M., E. P. Tanner, C. A. Harper, P. D. Keyser, and J. J. Morgan. 2012. Northern bobwhite survival related to movement on a reclaimed surface coal mine.

Venturato, E., P. Cavallini, P. Banti, and F. Dessì-Fulgheri. 2009. Do radio collars influence mortality and reproduction? A case with ring-necked pheasants (Phasianus colchicus) in Central Italy. European Journal of Wildlife Research 55:547-551. doi: 10.1007/s10344009-0271-6.

West, A. S., P. D. Keyser, and J. J. Morgan. 2012. Northern Bobwhite Survival, Nest Success, And Habitat Use In Kentucky During The Breeding Season.

Winder, V. L., L. B. McNew, A. J. Gregory, L. M. Hunt, S. M. Wisely, and B. K. Sandercock. 2014. Effects of wind energy development on survival of female greater prairie-chickens. Journal of Applied Ecology 51:395-405. doi: 10.1111/1365-2664.12184. 